\title{
Formation of the Equiaxed Zone in Ingots and \\ Macro-segregation in Steel Ingots*
}

\author{
By Atsumi $O \mathrm{HNO}^{* *}$ and Hiroshi $\mathrm{SO} D A^{* *}$
}

\section{Synopsis}

99.99\% pure aluminum, commercial grade aluminum $(99.8 \%)$ containing $0.13 \%$ iron and $0.07 \%$ silicon, and aluminum-copper alloy containing 0.1 to $4 \%$ copper were solidified in graphite molds under static and vibrating conditions. To provide sufficient evidence to show how, or more specifically, when the equiaxed grains begin to form, inserts made of 18-8 stainless steel gauze of 30 mesh were placed in the mold.

The equiaxed region in castings has been shown to be composed of crystallites formed at the initial stage of solidification. The mechanism of the formation of these crystallites is probably partial dendrite remelting due to temperature fluctuations in the melt. The crystallites originated at the initial stage in the upper part of the growing interface precipitate along the interface to the bottom. Some of these crystallites were carried up into the bulk of the liquid. The crystallites that survive finally precipitated onto the initial heap.

The formation mechanisms of negative segregation, inverted $V$-segregation, and normal $V$-segregation were explained based on the experimental results.

\section{Introduction}

The freezing of a casting can be divided into three regions; a chill zone formed near the mold wall, a columnar zone, and an equiaxed region at the center of the casting. The main purpose of this paper is to study the origin of the grains in the equiaxed region. The proposed mechanisms for the equiaxed grain formation in the cast structure ${ }^{1-5)}$ differ considerably.

Winegard and Chalmers ${ }^{1)}$ pointed out that the molten central region of an ingot could be constitutionally undercooled, because of the solute layer at the growing interface. In the undercooled region, nucleation of particles could occur, giving rise to the equiaxed crystals.

Genders $^{2)}$ and Chalmers ${ }^{3)}$ stated that the crystallites from which the equiaxed grains are formed originate at the mold walls during pouring and that some of these survive the superheat and drift away from the interface to the center of the casting where they ultimately grow to the final equiaxed grain size.

Jackson et al. ${ }^{4)}$ suggested that the equiaxed crystals arise from the partial remelting of dendrites as a result of temperature fluctuations which is due to convection in the melt during growth of the columnar zone. Southin $^{5)}$ observed that, in addition to the three accepted zones in a casting, viz. chill, columnar, and equiaxed, a fourth dendritic zone is formed across the top of the ingot as a result of chilling. He concluded that the showering down of dendrite particles from this layer gives rise to the equiaxed region.

Pouring turbulence and convection in the melt must play major roles in influencing the overall cast structure. Any change in the convective pattern will alter the rate of heat transfer, affect the transport of solid crystallites in the liquid and also control the degree of dendrite remelting. It has been shown that reducing convection by means of mechanical barriers ${ }^{6)}$ or magnetic fields ${ }^{7)}$ can lead to a reduction in size or even complete elimination of the equiaxed zone. These results however do not provide sufficient evidence to clearly show how, or more specifically, when the equiaxed grains begin to form.

The present investigation was conducted in an attempt to ascertain the stage in which the equiaxed grains originate during solidification and therefore help to provide a further understanding of the solidification of castings, especially the formation mechanism of macro-segregation in large steel ingots.

\section{Experiments}

Experimental studies were carried out with $99.99 \%$ pure aluminum, commercial grade aluminum (99.8\%) containing $0.13 \%$ iron and $0.07 \%$ silicon, and aluminum-copper alloys containing 0.1 to $4 \%$ copper. The molds used were made of electrode graphite and had the following dimensions: external diameter $50 \mathrm{~mm}$, height $120 \mathrm{~mm}$, a mold cavity $100 \mathrm{~mm}$ deep, and a diameter $35 \mathrm{~mm}$.

The metals were melted in graphite crucibles and poured at $750^{\circ} \mathrm{C}$. The mold was kept at room temperature before casting. The vibration apparatus con-

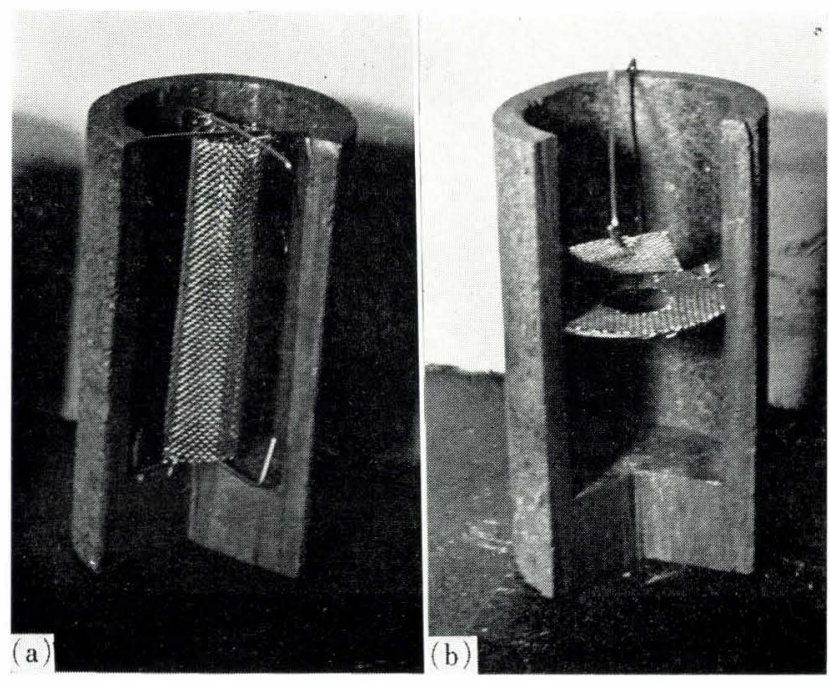

Photo. 1. Molds with gauze barriers

(a) Vertical barrier

(b) Horizontal barrier

* Originally published in Tetsu-to-Hagané, 55 (1969), 475 in Japanese. English version received June 18, 1969.

** Department of Metallurgy, Chiba Institute of Technology, Narashino 275. 

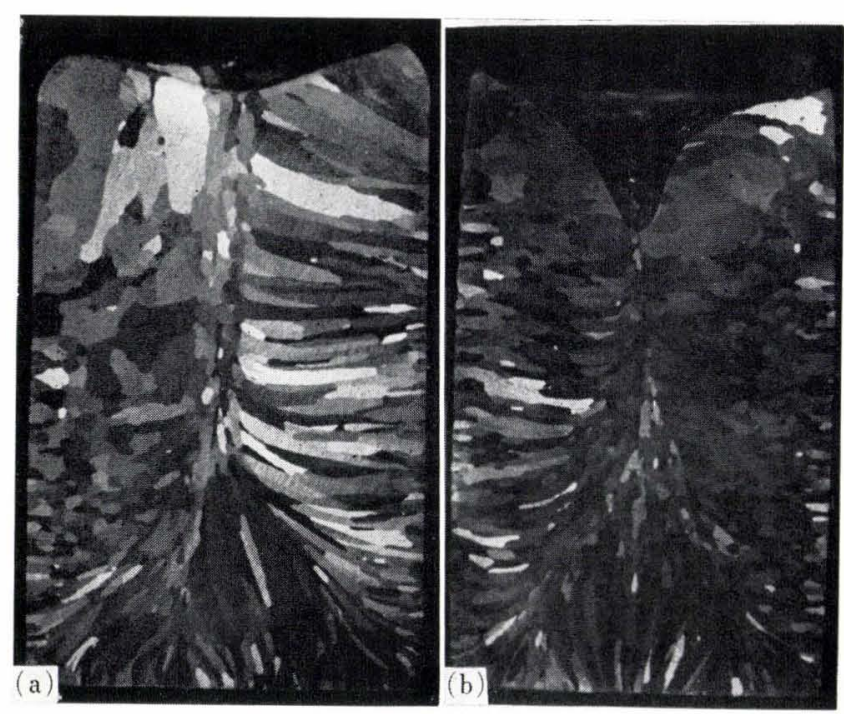

Photo. 2. $99.99 \%$ pure aluminum cast into graphite molds at $750^{\circ} \mathrm{C}(\times 1.4)(\times 3 / 4)$

(a) Mold stationary

(b) Mold vibrating sisted of a $50 \mathrm{c} / \mathrm{sec}$ electro-magnetic vibrator, the amplitude in the order of $0.2 \mathrm{~mm}$ was controlled by varying the applied voltage. Inserts shown in Photo. 1 were placed in the mold in some of the experiments. They were made of 18-8 stainless steel gauze of 30 mesh. A "trap door" barrier was held horizontally in the mold at a distance of 10,20 , and $30 \mathrm{~mm}$ respectively from the top. Another barrier of a cylindrical shape was held axially in the mold.

Later experiments were done by using a U-shaped graphite crucible as the mold. In order to prevent penetration of water, the outside of the crucibles was coated with sodium silicate and then baked at $1000^{\circ} \mathrm{C}$.

\section{Results}

The macrostructure of $99.99 \%$ aluminum ingots solidified under static and vibrating conditions showed no tendency in forming an equiaxed structure as shown in Photo. 2. The ingots consisted mostly of columnar grains.

The macrostructure of $99.8 \%$ aluminum ingots solidified under static condition showed a similar structure to that of $99.99 \%$ aluminum consisted merely
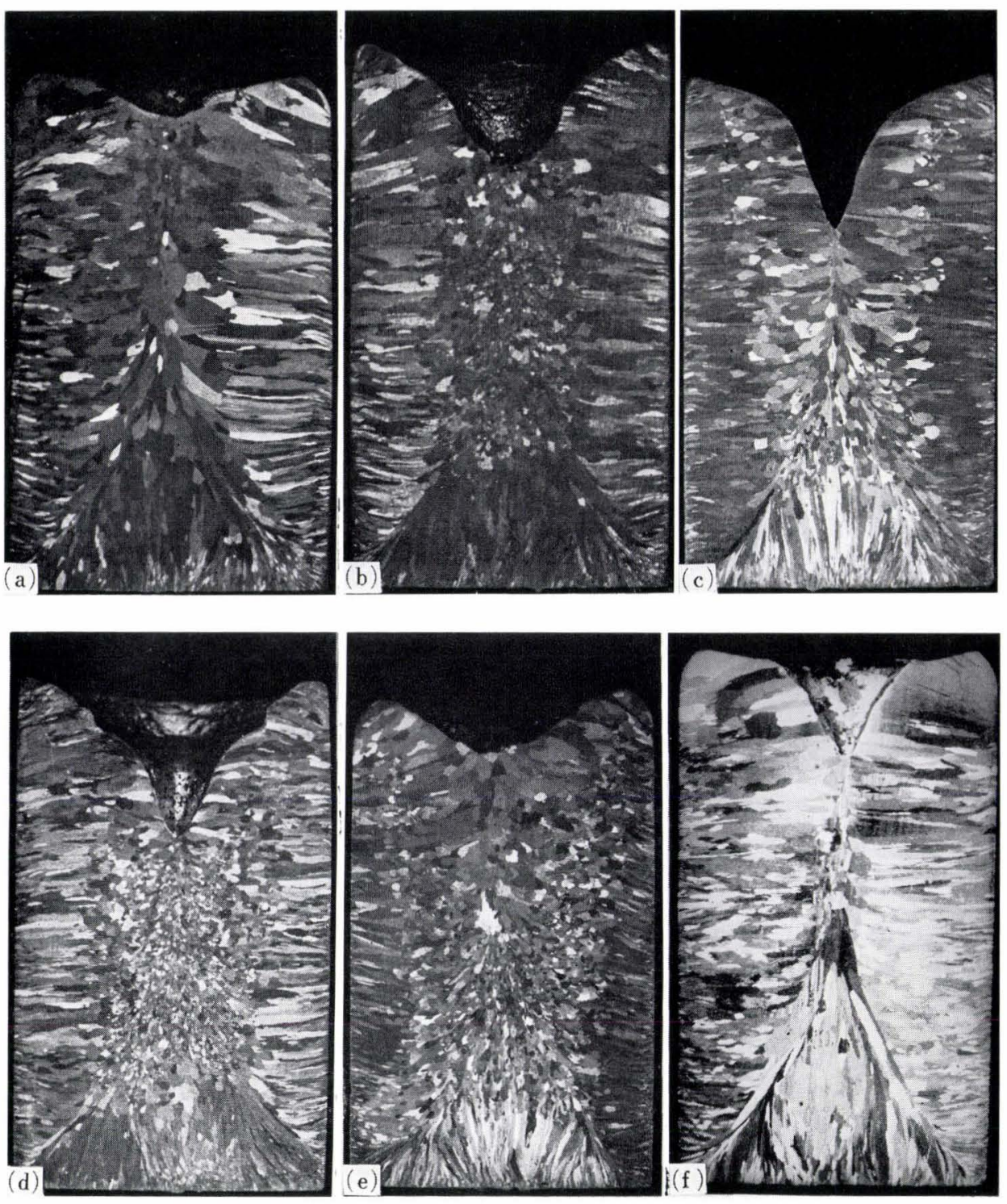

Photo. 3.

Macrostructures of cast ingots of $99.8 \%$ aluminum containing $0.13 \%$ iron and $0.07 \%$ silicon $(\times 1.4)(\times 3 / 4)$

(a) Mold stationary

(b) Mold vibrating

(c) Mold vibrated only for $2 \mathrm{sec}$ after pouring $(15 \mathrm{sec}$ required for total solidification)

(d) Mold vibrated only for $4 \mathrm{sec}$ after pouring ( 15 sec required for total solidification)

(e) Mold vibrated only for last $10 \mathrm{sec}$ of solidification (stationary for $5 \mathrm{sec}$ after pouring)

(f) Mold vibrated only for last 8 sec of solidification (stationary for $7 \mathrm{sec}$ after pouring) 
of columnar grains, as shown in Photo. 3 (a). However the resulting structure under vibrating conditions showed a tendency to form an equiaxed structure as shown in Photo. 3 (b). Commercial grade aluminum $(99.8 \%$ ) was also solidified in a graphite mold which was vibrated only for 2 sec just after pouring. The resulting structure is shown in Photo. 3 (c) which does not differ much from that of Photo. 3 (a). However, a few large equiaxed grains of U-shape can be observed in the columnar zone. When the metal was solidified in a mold which was vibrated only for $4 \mathrm{sec}$ just after pouring, the resulting structure showed the same type of structure as that in Photo. 3 (b) which was obtained with vibration for the overall solidification time of 15 sec. When a graphite mold was kept stationary for 5 sec after pouring and then vibrated until the solidification was complete, the resulting structure was similar to that in Photo. 3 (c). When a graphite mold was kept stationary for $7 \mathrm{sec}$ after pouring and then vibrated until the solidification was complete, the resulting structure was similar to that in Photo. 3 (a) and showed no tendency to form an equiaxed structure.

Commercial grade aluminum $(99.8 \%$ ) was poured into a mold in which the central region was isolated mechanically with a cylindrical barrier of 30 mesh stainless steel gauze. The metal was solidified under vibrating conditions, and a short columnar zone and a fine equiaxed structure were produced in the outer part of the barrier as shown in Photo. 4 (a). The structure of the outer part of the barrier shown in Photo. 4 (a) is similar to that in Photo. 3 (b). The structure of the inner part is similar to that in Photo. 3 (a) which contained mostly of columnar grains. With a horizontal barrier, a fine equiaxed region appeared only on the barrier as shown in Photo. 4 (b). The structure above the barrier was similar to that in
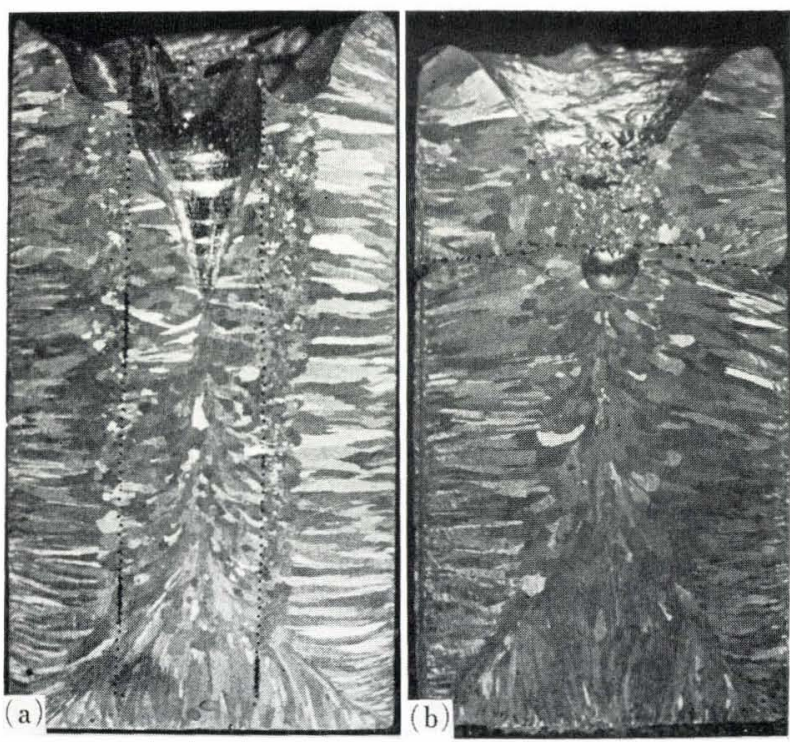

Photo. 4. Effect of mechanical barriers on the solidified structure of $99.8 \%$ aluminum, cast into vibrating graphite molds from $750^{\circ} \mathrm{C}(\times 1.4)(\times 3 / 4)$

(a) Mold with a cylindrical barrier

(b) Mold with a horizontal barrier
Photo. 3 (b), and below the barrier was similar to that in Photo. 3 (a).

The macrostructure of aluminum-2\% copper alloy ingots solidified under normal conditions contained a peripheral zone of columnar grains and a central equiaxed region. Vibration produced a more marked grain refinement in the equiaxed region. It was observed that the equiaxed region extended as the copper content increased as shown in Photo. 5. The macrostructure of an aluminum-4\% copper alloy consisted entirely of equiaxed grains. There was little effect of vibration on the grain size in ingots which were solidified under static or vibrating conditions as shown in Photo. 6.

Aluminum-0.2\% copper alloy of about $800 \mathrm{~g}$ was also melted in a graphite crucible at $750^{\circ} \mathrm{C}$. The

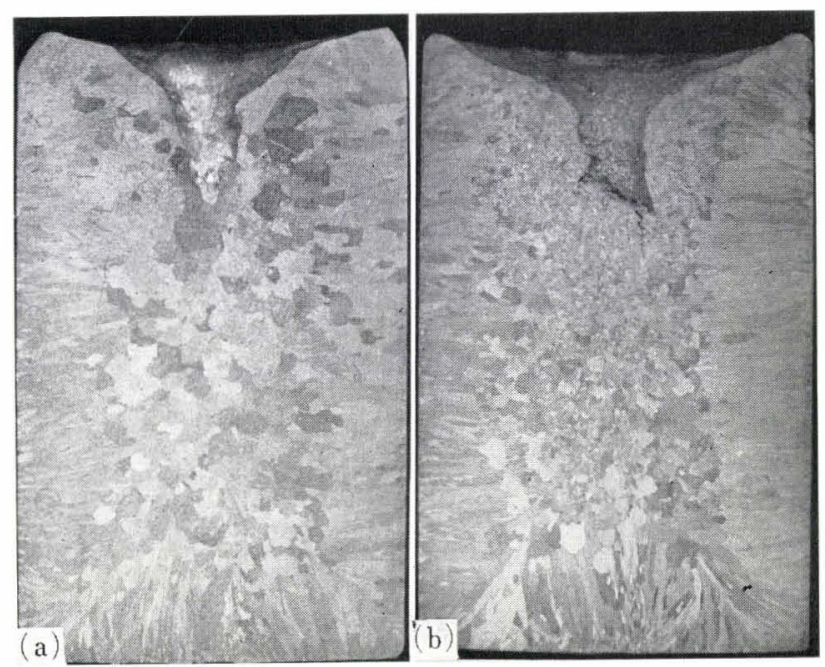

Photo. 5. Macrostructures of cast ingots of aluminum- $2 \%$ copper alloy $(\times 1.4)(\times 3 / 4)$

(a) Mold stationary

(b) Mold vibrating

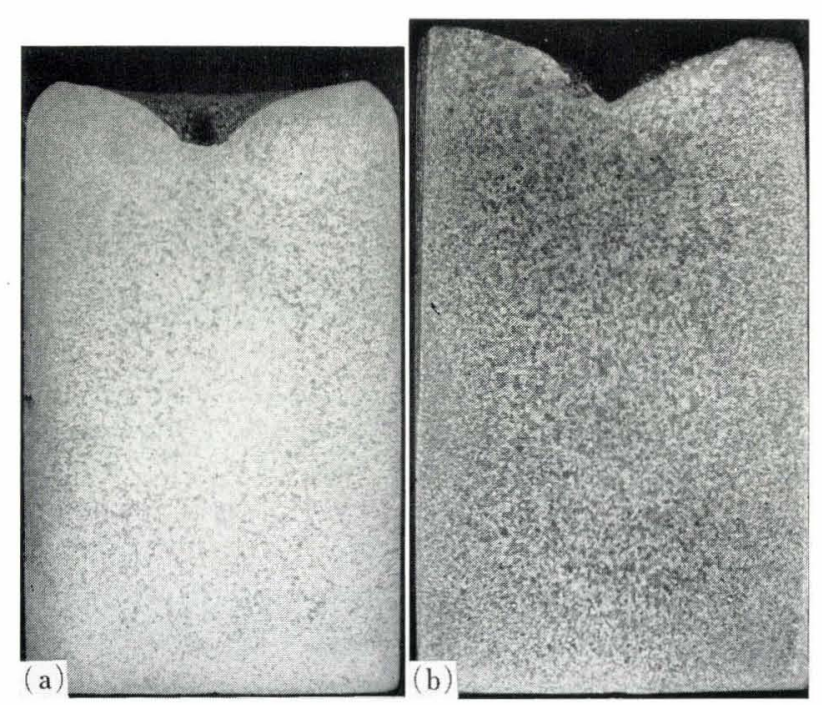

Photo. 6. Macrostructures of cast ingots of aluminum-4\% copper alloy $(\times 1.4)(\times 3 / 4)$

(a) Mold stationary

(b) Mold vibrating 

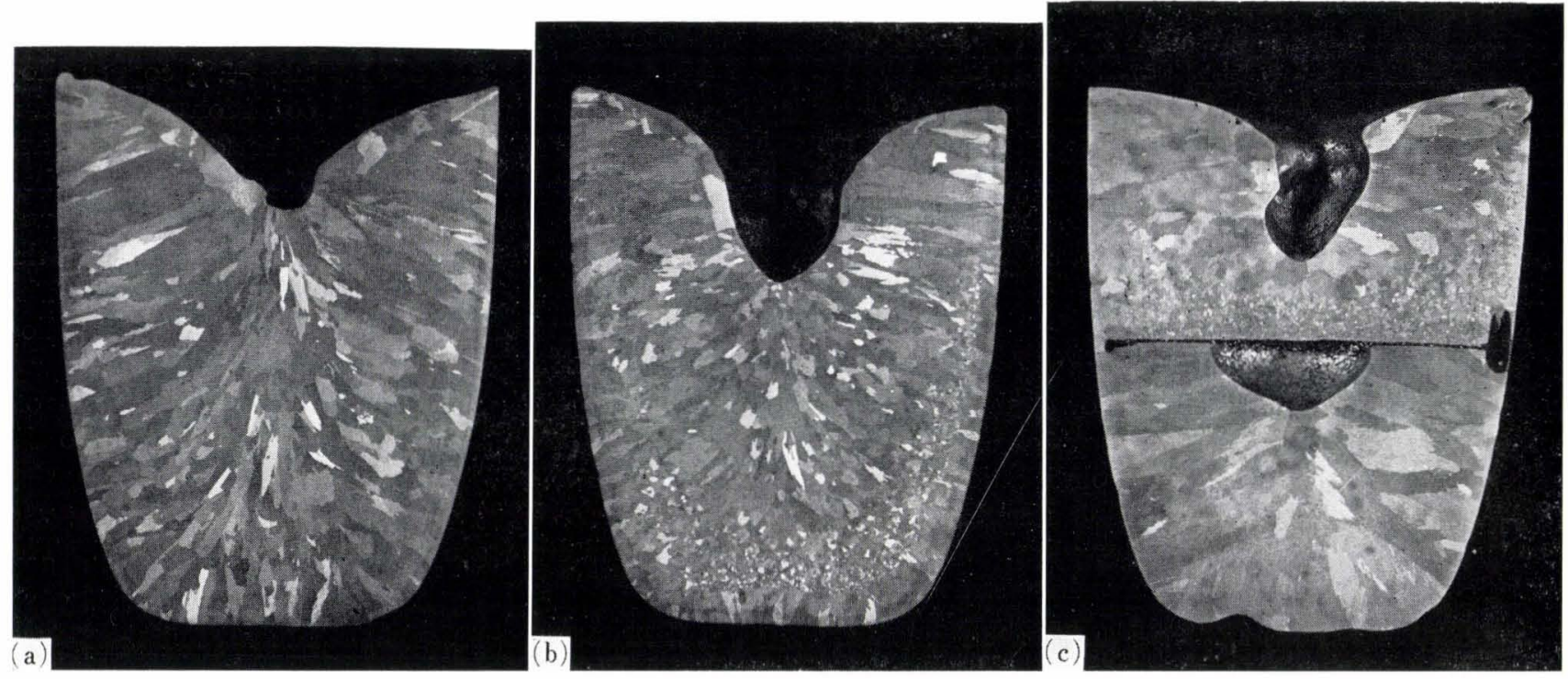

Photo. 7. Macrostructures of aluminum $-0.2 \%$ copper alloy ingots $(\times 0.8)(\times 3 / 4)$

(a) Molten surface stationary

(b) Molten surface vibrating

(c) Molten surface vibrating

crucible was then immersed in water to cool the molten metal. When the alloy was solidified in the crucible the outside of which was coated with sodium silicate, the solidified structure showed no equiaxed region but contained columnar grains with a few large equiaxed grains, as shown in Photo. 7 (a).

With the crucible the outside of which was coated with sodium silicate except for $30 \mathrm{~mm}$ from the top, the resulting structure consisted of three zones, columnar, fine equiaxed grain zone, and secondary columnar zone in the center of the ingot as shown in Photo. 7 (b). In this case, it was observed that the molten surface was slightly vibrating at the initial stage of solidification. The vibration was considered to be due to the penetration of steam into the crucible wall. When a horizontal barrier was placed in the crucible, the fine equiaxed grain region appeared in U-shape on the barrier. Under the barrier there were only large columnar grains and no equiaxed grains were found as shown in Photo. 7 (c).

\section{Discussion 1}

\section{Formation Mechanism of Equiaxed Zone}

Various theories which have been proposed to explain the equiaxed grain formation in the center of ingots will be discussed with regard to the present work.

\section{Constitutional Undercooling}

Winegard and Chalmers ${ }^{1)}$ pointed out that the molten central region of an ingot could be constitutionally undercooled, because of the solute layer at the growing interface. In this undercooled region nucleation of particles could occur, giving rise to the equiaxed crystals. To examine this theory, some experiments were carried out by using mechanical barrier. Here, the resulting macrostructures, as shown in Photos. 3 (c), (d), (e), and (f), clearly show that the drifting away of nuclei from the mold wall is not the essential mechanism of formation of the equiaxed region in castings.

The hypothesis of Chalmers ${ }^{3)}$ was based on the evidence obtained by placing a tube axially in the mold to stop the drift of nuclei from the vicinity of the mold wall to the central zone of ingot. In this experiment, it should be noted that the tube in the mold formed a separate mold and hence the molten metal in the inner region cooled at a lower rate than that in the outer part of the mold. Therefore, it was only natural that the two liquids formed different structures.

In the present work, a cylindrical-shaped barrier of stainless steel gauze of 30 mesh which allowed the liquid to pass through was used instead of the tube. In the resulting structure, the presence of the fine equiaxed grains only in the outer part of the cylindrical barrier can be explained by the remelting of dendrite arms but not by the nucleation theory.

The drifting away of nuclei from the mold wall can probably occur if the alloy contained enough solute to stop the growth of nuclei and form germ-shaped crysta[s on the mold wall. Using 0.1 to $4 \%$ copper alloys, the resulting structures showed that the width of the columnar zone decreased as the copper content increased.

\section{Showering from Freeze Over}

Southin ${ }^{2)}$ concluded that the showering down of dendrite particles from the coarse dendritic layer at the top surface gives rise to the equiaxed region. However, no evidence of a coarse dendritic layer at the top surface was found in the small ingot of $99.8 \%$ aluminum which had a large equiaxed zone when it was solidified in a vibrating mold as shown in Photo. 3 (b). The showering theory was not confirmed by the experiments with a cylindrical barrier, because there was no equiaxed region in the inner part while it existed in the outer part of the barrier. 
An aluminum- $0.2 \%$ copper alloy ingot had "a fourth layer" which was named by Southin as shown in Photo. 7 (a). This is not considered to be an essential source of the equiaxed grains because no equiaxed region was found there. Due to the vibration in the molten surface, a U-type equiaxed zone appeared as shown in Photo. 7 (b). With a horizontal barrier the precipitated grains appeared on the barrier in U-type shape indicating that these grains had fallen down from the upper sides of the growing interface but not from the fourth layer.

If the temperature of the top surface of the casting is lower than that of the mold wall, showering can occur first. However in the usual case it is hardly conceivable that the showering would occur prior to the remelting of the dendrite from the mold wall.

\section{Dendrite Arm Remelting}

Based on the experiments using organic compounds, Jackson et al. ${ }^{4)}$ suggested that convection plays a part in the dislodgement of dendrite arms growing from the mold wall. The present experiments proved the above theory using actual metals.

The resulting structures of the ingots cast in the molds which were vibrated for 2 or 4 sec after pouring clearly proved the dendrite remelting. The crystals were nucleated on the mold wall and grew until they formed germ-shaped crystals or dendrite arms with narrow necks which were to be easily separated away. Then the remelting will begin with the help of temperature fluctuations in the melt. The resulting structures which were obtained under vibrating conditions, with the horizontal or cylindrical barriers, can be clearly explained by dendrite remelting but not by the other above mentioned theories.

The remelting can occur easily on the upper part of the solid shell, because the most violent temperature fluctuations occur by means of surface movement at the point where the molten surface is in contact with the side of the solid shell.

In order to produce an equiaxed region in a casting, new crystals must not only form but also find their way to the center region of the casting, ahead of the dendritic interface. The new crystals formed along the upper sides of the casting by remelting can be carried either by convection current in the liquid or by their own gravity onto the solid shell at the bottom.

It is well known that the equiaxed zone often shows a graduation of grain size from large at the top to fine at the bottom. As the circulation in the liquid flows down the sides of the mold and turns to rise up at the center, some of these crystals will be carried up into the bulk of the liquid. Under normal conditions a fraction of those crystals will remelt as they move into the hotter liquid region in the center of the casting. The crystallites that survive then grow and finally precipitate onto the initial heap.

\section{Upper Part of Solid Shell}

If some dynamic motions are applied to the melt in the molds, the surface is most susceptible to vibration or movement thereby resulting in temperature fluctuations in the melt. Hence, the dendrite in the upper part was the most probable source of the new crystallites formed.

\section{Initial Stage}

When $99.8 \%$ pure aluminum was kept stationary in a mold for $7 \mathrm{sec}$ after pouring and then vibrated until the whole liquid solidified, the resulting structure was similar to that of the ingot which was solidified under static conditions. This is in contrast to the metal solidified with vibration only for the initial $4 \mathrm{sec}$ which showed a large equiaxed region.

This indicates that remelting occurs mainly in the early stage of solidification. Fine dendrite arms with narrow necks which are considered to be easily separated by remelting, are produced at the initial stage of solidification.

\section{Pouring Temperature}

When aluminum- $0.2 \%$ copper alloy of $800 \mathrm{~g}$ was poured into a graphite crucible at $680^{\circ} \mathrm{C}$, the resulting structure contained a very thin solid shell of columnar crystals and a columnar zone which was surrounded by a U-shaped equiaxed zone as shown in Photo. 8 (a).
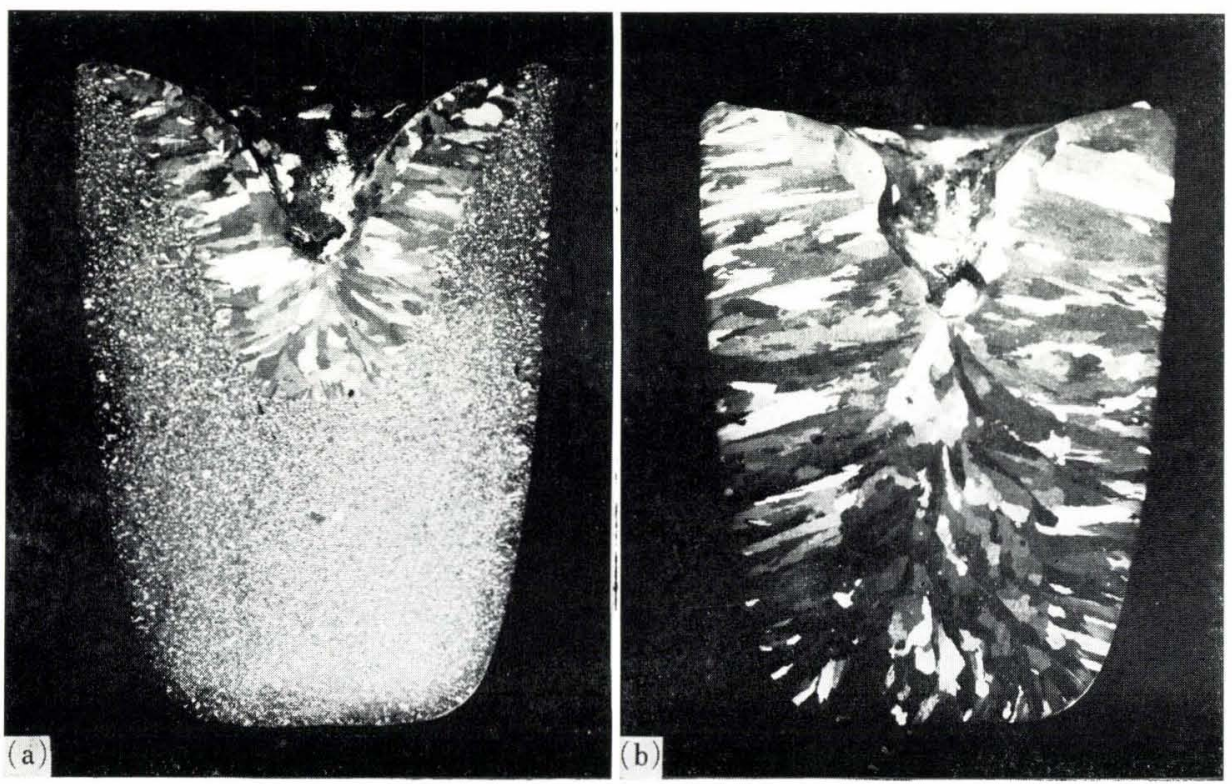

Photo. 8.

Effect of pouring temperature on the cast structure of aluminum$0.2 \%$ copper alloy ingots $(\times 0.8)$ $(\times 3 / 4)$

(a) Poured at $680^{\circ} \mathrm{C}$

(b) Poured at $730^{\circ} \mathrm{C}$ 
The equiaxed area decreased as the pouring temperature rose and finally the equiaxed zone disappeared in the ingot cast at $730^{\circ} \mathrm{C}$, as shown in Photo. 8 (b). This is considered to be due to the dissolution of the fine floating crystals in the hotter bulk of the liquid region.

\section{Discussion 2}

\section{Formation Mechanism of Macro-segregation in Steel Ingots}

With the above theory, the formation mechanisms of negative segregation, inverted $\mathrm{V}$-segregation, and normal $\mathrm{V}$-segregation in steel ingots can be clearly understood.

\section{Negative Segregation}

Many studies have been done on the formation mechanism of the macro-segregation in steel ingots. However, most of the reports were based on the observation of solidified structures and on the results of chemical analysis of the ingots because it seemed impossible to observe the solidification phenomenon of steel in molds. Recently, the R.I. technique ${ }^{8), 9)}$ has been often used to understand the solidification phenomenon of steel ingots, but it is still considered difficult to observe the behavior of solidified particles in the melt.

The oldest proposal for the formation mechanism of the negative segregation in steel ingots was made by the Heterogeneity Committee of the Iron and Steel Institute of England. ${ }^{10)}$ This theory is known as " the settling crystal theory" and states that at optional points of molten steel, high purity crystals nucleate and grow, which have greater density than the melt surrounding them. So, pure crystals fall down in the melt and accumulated at the lower portion of a steel ingot, resulting in the negative segregation zone. The Committee $^{11)}$ re-examined this explanation and corrected it by stating that the main cause is the floating up of segregated melt from the lower part of the ingot to the upper part rather than the falling down of high pure crystals. Northcott, ${ }^{12)}$ West, ${ }^{13)}$ and Gray et al. ${ }^{14)}$ made experiments using horizontal ingots, and discussed the results with the settling crystal theory.

Momose ${ }^{14)}$ pointed out that this theory holds many unsolved questions. There is no definite answer for the question, whether or not random nucleation in the melt can produce enough precipitation to form the negative segregation zone. If the precipitation of crystals is the main cause for the formation of the negative segregation zone, the precipitated crystals will be purer at the part nearer to the bottom of ingots where melt solidifies first. Therefore, the concentration of solute elements should be the lowest at this part. However, as observed usually on large steel ingots, the center of the negative segregation zone where the concentration of solute elements is the lowest, has been found at one third from the bottom of the ingots. This position differs from the center, estimated from the settling crystal theory. This is considered to be due to the lack of information for the origin of settling crystals.

The present work on the formation mechanism of the equiaxed zone helps to solve this problem. Using the R.I. technique for the solidification of a steel ingot, $\mathrm{Kohn}^{8)}$ observed that fallen crystals formed a funnelshaped mound, and the center of the mushy zone sank because solid materials are slightly denser than liquid steel, as shown in Fig. 1. This is considered to confirm the author's theory. Schematic diagrams which were drawn based on this theory are given in Fig. 2. At first, a violent wave motion will occur in the molten metal during pouring as shown in Fig. 2 (a). A solid shell forms on the mold wall and dendrite remelting occurs in the front of the solid shell, and the fine crystals fall down to the bottom. Kosmider et al. ${ }^{16)}$ reported that the thermal convection occurs in the front of the interface. Cole et al. ${ }^{17)}$ observed the thermal fluctuations in the front of the solid shell of tin during solidification. So, even after filling up the mold with molten metal there still exists thermal fluctuations which are caused by the thermal convection in the front of the interface. The crystals are separated at the front by dendrite remelting, then fall along the interface and precipitate to the bottom where the solute was already enriched. Some of the fine crystals are carried up into the bulk liquid by thermal convection and float up until the temperature decreases, as shown in Fig. 2 (b). As the dendrite arms grow and the thermal convection decreases, the dendrite remelting action stops. At this stage, some crystals on the top of the solidified zone of precipitated crystals can grow by temperature gradient. Maekawa et al. ${ }^{18)}$ reported that there was a band of large crystals with large particles of non-metallic inclusion in the equiaxed zone near the bottom. Photograph 9 shows coarse crystals in the equiaxed zone of

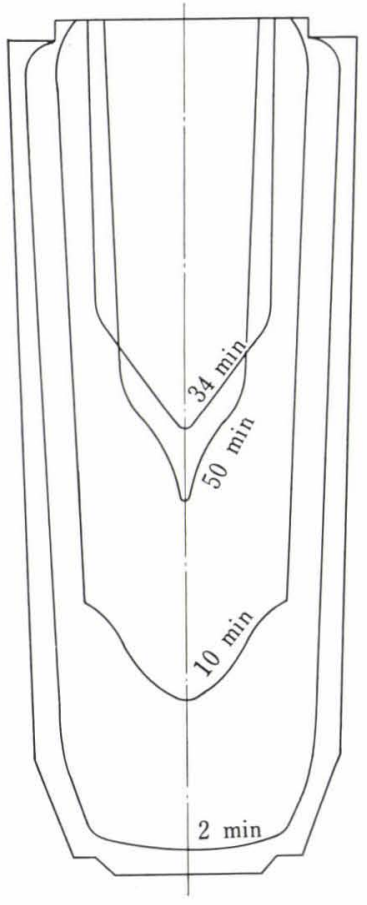

Fig. 1. Outlines of the radioactive zone boundaries in 3.5-t steel ingot; tracers added at various times after teeming ${ }^{8)}$ 

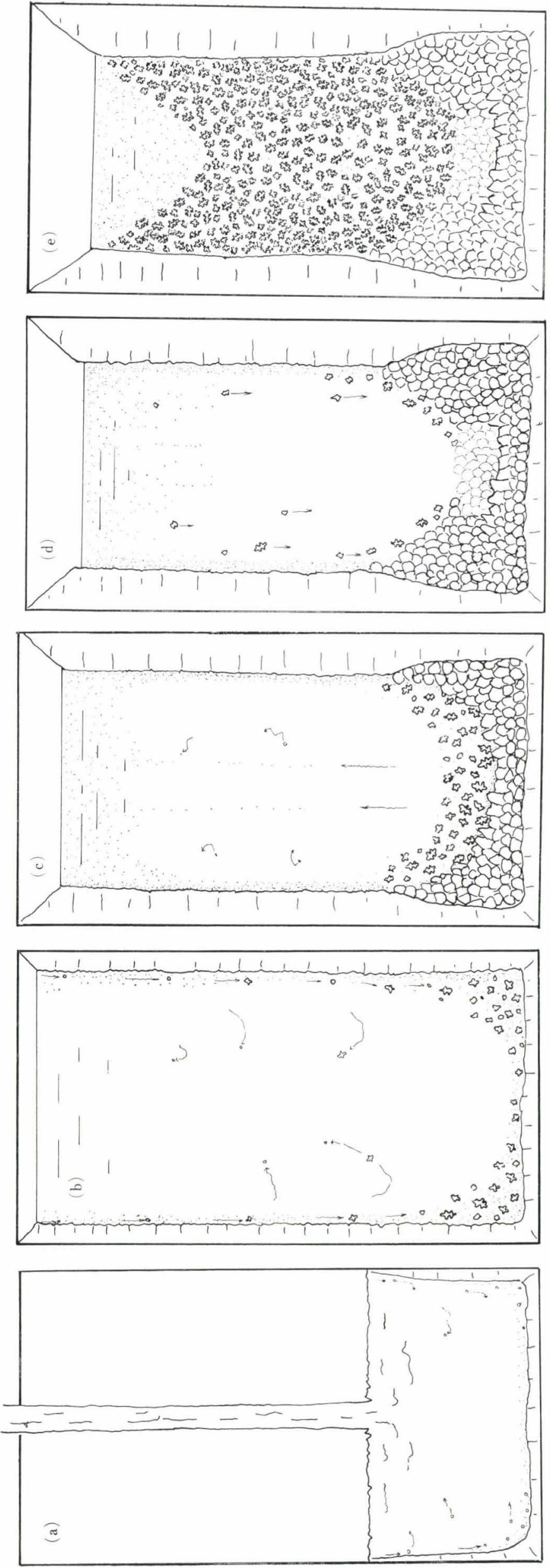
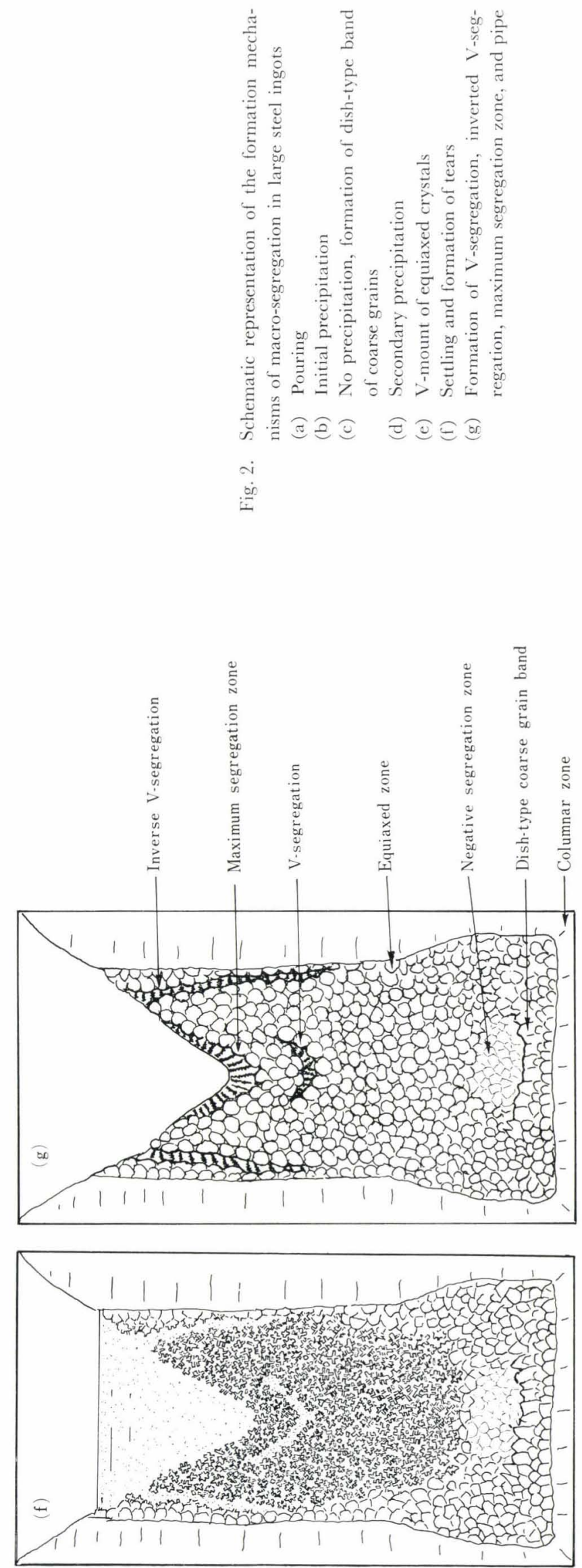


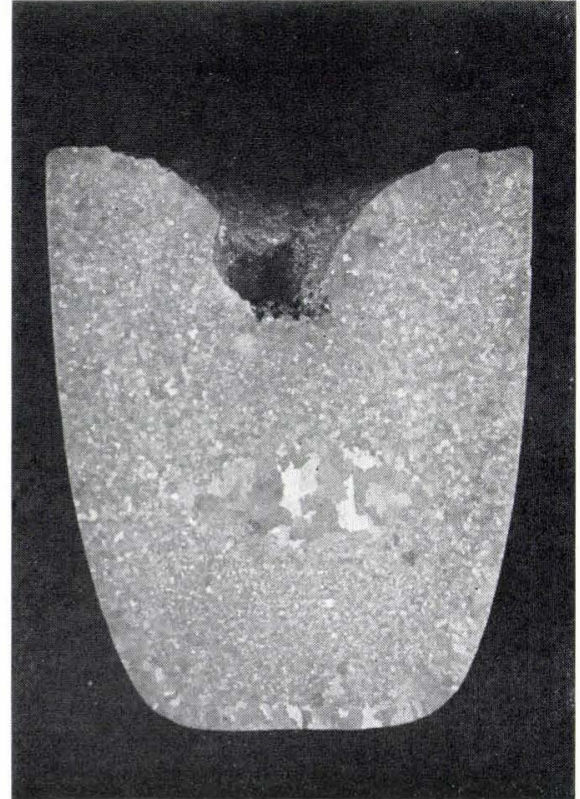

Photo. 9. Coarse grains in aluminum-copper alloy cast ingot $(\times 0.8)(\times 3 / 4)$

aluminum-2\% copper alloy. The crystals below the coarse crystals are much smaller than those of the above suggesting that the precipitation of crystals took place twice: initial and secondary precipitations, as mentioned before.

The solute in the upper central zone of the precipitated crystal zone, namely " mushy zone," goes up by compositional convection or diffusion while the outer part of the precipitated zone solidifies, including the enriched solute as shown in Fig. 2 (c). Momose ${ }^{15)}$ observed that the temperature at the central part of the negative segregation zone was constant for several hours during solidification. His results seemed to prove the present explanation.

As the temperature of the bulk liquid decreases, the floating fine crystals grow and then precipitate onto the initial heap of crystals. The crystals will contain much solute between their dendrite arms because the solute was already enriched in the bulk liquid. Therefore, the negative segregation zone remains in the upper part of the initial heap of crystals as shown in Fig. 2 (d). Then, more crystals precipitate forming a $\mathrm{V}$-shaped mound as shown in Fig. 2 (e).

Because the connection between each crystal in the $\mathrm{V}$-shaped mound is considered to be very weak, tears form in this zone when the lower central part of the equiaxed crystal zone settles as shown in Fig. 2 (f).

Finally, the liquid in the tears solidifies, forming $\mathrm{V}$ segregation and inverted $\mathrm{V}$-segregation. The solute- enriched residue liquid in the central upper part forms a maximum segregation zone of coarse dendrites with a shrinkage pipe as shown in Fig. 2 (g).

\section{Conclusions}

The equiaxed region in castings has been shown to be composed of crystallites formed during the initial stage of solidification. The mechanism of formation of these crystallites is probably dendrite remelting due to temperature fluctuations in the melt. There are roughly two types of equiaxed grains : very fine grains which originated in the upper part of the growing interface at the initial stage of solidification and fall along the growing interface to the bottom, and larger grains which originated at the initial stage floating in the bulk liquid before precipitating to the top of the initial heap.

The formation mechanisms of macro-segregation in large steel ingots were explained based on the above theory.

\section{Acknowledgements}

The authors are grateful to Dr. K. Hata for many helpful discussions. The authors would also like to express their appreciation to Mr. S. Hayashi for performing several of the experiments.

\section{REFERENCES}

1) W. C. Winegard and B. Chalmers: Trans. Am. Soc. Metals, 46 (1954), 1214.

2) R. Genders: J. Inst. Metals, 35 (1926), 259.

3) B. Chalmers: J. Australian Inst. Metals, 8 (1965), 255.

4) K. A. Jackson, J. D. Hunt, D. R. Uhlmann, and T. P. Seward III : Trans. AIME, 236 (1966), 149.

5) R. T. Southin: Trans. AIME, 239 (1967), 220.

6) G. S. Cole and G. F. Bolling: Trans. AIME, 233 (1965), 1568.

7) D. R. Uhlmann, T. P. Seward III, and B. Chalmers: Trans. AIME, 236 (1966), 527.

8) A. Kohn: The Solidification of Metals, (1967), 356, The Iron and Steel Inst. (U.K.).

9) K. W. Andrews and C. R. Gomer: The Solidification of Metals, (1967), 363, The Iron and Steel Inst. (U.K.).

10) Reports on the Heterogeneity of Steel Ingots, J. Iron Steel Inst., 113 (1926), 39.

11) Reports on the Heterogeneity of Steel Ingots, J. Iron Steel Inst., 135 (1937), 1.

12) L. Northcott: J. Iron Steel Inst., 135 (1937), 363.

13) D. R. F. West: J. Iron Steel Inst., 164 (1950), 182.

14) B. Gray: J. Iron Steel Inst., 182 (1956), 366.

15) A. Momose: Trans. ISIJ, 9 (1969), 21.

16) H. Kosmider et al.: Stahl u. Eisen, 77 (1957), 133.

17) G. S. Cole and W. C. Winegard: Canadian Met. Quart., 1 (1962) 1, 29.

18) S. Maekawa, M. Fukumoto, and K. Taniguchi: Tetsu-toHagané, 54 (1968) 10, S 700. 